\title{
Acromegaly remission, SIADH and pituitary function recovery after macroadenoma apoplexy
}

\author{
E Sanz-Sapera1', S Sarria-Estrada ${ }^{2}$, F Arikan ${ }^{3}$ and B Biagetti ${ }^{1}$ \\ 'Endocrinology, ${ }^{2}$ Radiology, and ${ }^{3}$ Neurosurgery, Vall d'Hebron Hospital, Barcelona, Spain
}

Correspondence should be addressed to B Biagetti

Email

bbiagetti@vhebron.net

\section{Summary}

Pituitary apoplexy is a rare but potentially life-threatening clinical syndrome characterised by ischaemic infarction or haemorrhage into a pituitary tumour that can lead to spontaneous remission of hormonal hypersecretion. We report the case of a 50-year-old man who attended the emergency department for sudden onset of headache. A computed tomography (CT) scan at admission revealed pituitary haemorrhage and the blood test confirmed the clinical suspicion of acromegaly and an associated hypopituitarism. The T1-weighted magnetic resonance imaging (MRI) showed the classic pituitary ring sign on the right side of the pituitary. Following admission, he developed acute-onset hyponatraemia that required hypertonic saline administration, improving progressively. Surprisingly, during the follow-up, IGF1 levels became normal and he progressively recovered pituitary function.

\section{Learning points:}

- Patients with pituitary apoplexy may have spontaneous remission of hormonal hypersecretion. If it is not an emergency, we should delay a decision to undertake surgery following apoplexy and re-evaluate hormone secretion.

- Hyponatraemia is an acute sign of hypocortisolism in pituitary apoplexy. However, SIADH although uncommon, could appear later as a consequence of direct hypothalamic insult and requires active and individualised treatment. For this reason, closely monitoring sodium at the beginning of the episode and throughout the first week is advisable to guard against SIADH.

- Despite being less frequent, if pituitary apoplexy is limited to the tumour, the patient can recover pituitary function previously damaged by the undiagnosed macroadenoma.

\section{Background}

Pituitary apoplexy is a potentially life-threatening event. It results from haemorrhagic event or infarction of a preexisting pituitary adenoma or within a physiologically enlarged gland (e.g. pregnancy) $(1,2)$. It is usually observed in patients with non-functioning adenomas; however, it has also been reported in functioning adenomas $(3,4)$. Headache is the main symptom, and it can sometimes be accompanied by visual disturbances and/or ocular palsy (2).
Although apoplexy is often followed by hypopituitarism in non-functioning adenomas, in functioning ones, it may promote remission, and the progressive recovery of previously damaged glandular function has also been reported $(5,6)$.

Hyponatraemia can occur secondary to hypopituitarism (hypocortisolism) or, rarely, to inappropriate antidiuretic hormone (ADH) secretion (7). 
We report the rare case of a patient with a previously undiagnosed and untreated acromegaly, which presented with pituitary apoplexy. Severe related SIADH hyopnatraemia developed 1 week after admission, during the follow-up a spontaneous remission of the acromegaly was seen, followed finally by progressive pituitary gland function recovery.

\section{Case presentation}

A 50-year-old man was admitted to the emergency department with acute onset, unbearable headache. On examination, the patient had acromegaly features, and was slightly hypotensive and dazed. Fundus examination was unremarkable. There was no papilloedema.

\section{Investigation}

A computerised tomography (CT) scan revealed pituitary haemorrhage, and pituitary apoplexy was confirmed when the T1-weighted magnetic resonance imaging (MRI) showed the classic pituitary ring sign on the right side of the pituitary (Fig. 1). Blood tests were unremarkable beyond a slightly below normal limit of sodium $131 \mathrm{mEq} / \mathrm{L}$ (135-145). The hormonal profile under dexamethasone was thyroid-stimulating hormone: $0.8 \mathrm{mU} / \mathrm{L}(0.5-4.7)$, free thyroxine: $1.03 \mathrm{ng} / \mathrm{dL}(0.80-1.76)$, random cortisol: $2.06 \mu \mathrm{g} / \mathrm{dL} \quad(5.3-22.4)$, follicle-stimulating hormone: $10.3 \mathrm{U} / \mathrm{L}$ (1.42-15.4), luteinising hormone: $0.5 \mathrm{U} / \mathrm{L}$ (1.24-7.8), total testosterone: $23.8 \mathrm{ng} / \mathrm{mL}$ (241-827), prolactin: $3.1 \mathrm{ng} / \mathrm{mL}(2.1-17.7)$ and IGF1 $701 \mathrm{ng} / \mathrm{mL}$ (119-307) with random GH: $11 \mathrm{ng} / \mathrm{mL}(0.0-3.0)$.

\section{Treatment}

Urgent treatment with intravenous glucocorticoids and fluids was initiated, headache continued and took several days to improve. He began on dexamethasone $2 \mathrm{mg} / 8 \mathrm{~h}$ the first day, $2 \mathrm{mg} / 12 \mathrm{~h}$ the second and third day and then was tapered to hydrocortisone $20 \mathrm{mg}$ per day (10-5-5 mg) that was well tolerated. Suddenly on the seventh day after admission, he became worse, with increased headache, tiredness and trouble concentrating. The blood test revealed severe hyponatraemia 110 (135-145 mmol/L), hypo-osmolality $271 \mathrm{mosmol} / \mathrm{kg}$ (280-295) and renal excretion of sodium $50 \mathrm{mmol} / \mathrm{L}$. Treatment was started with i.v. hydrocortisone $100 \mathrm{mg} / 8 \mathrm{~h}, 3 \%$ hypertonic saline at $60 \mathrm{~mL} / \mathrm{h}$ for the first $2 \mathrm{~h}$ with a reduced rate of $35 \mathrm{~mL} / \mathrm{h}$ during the last $20-24 \mathrm{~h}$, along with water restriction,
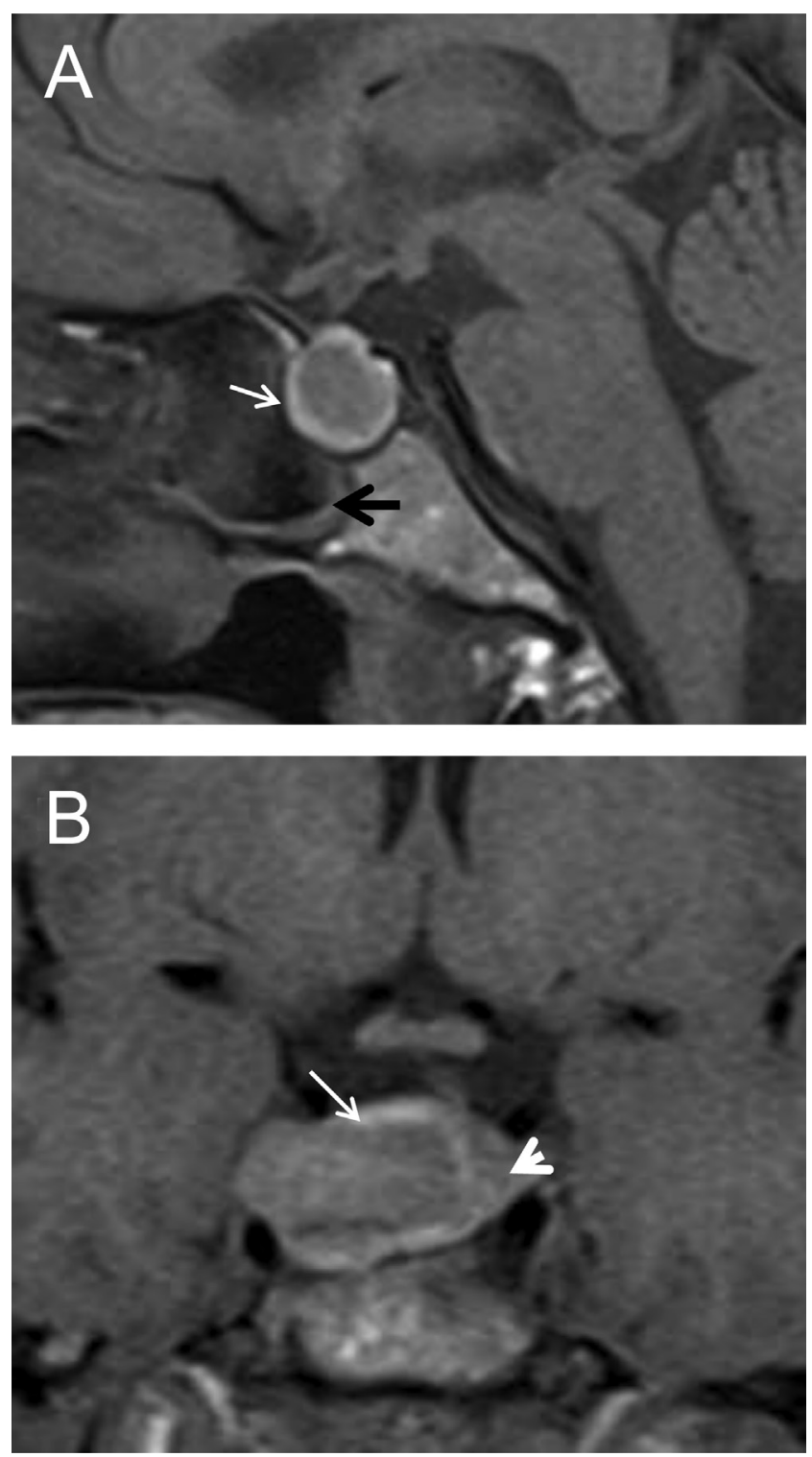

Figure 1

A 50-year-old man with pituitary apoplexy. Sagittal (A) and coronal (B) T1-weighted images. The pituitary is enlarged with remodelling of the pituitary fossa. Intrinsic high T1 signal (white arrow) is seen in a pituitary mass which has remodelled the pituitary fossa. The pituitary gland is displaced to the left (head arrow). The sphenoid sinus has mucosal thickening (black arrow).

leading to progressive sodium normalisation. The hormonal profile revealed that free thyroxine persisted at normal levels, testosterone levels improved and IGF-1 had dropped to $350 \mathrm{ng} / \mathrm{mL}$. Given he was under standard maintenance dose of hydrocortisone, we empirically treated with high intravenous doses. Taking into account the tapering dose of hydrocortisone had been well tolerated for the patient, the hyponatraemia episode occurred 1 week after admission, and the biochemical 
reports were hypo-osmolality and high natriuresis, SIADH was diagnosed.

\section{Outcome and follow-up}

The patient was discharged 1 week later with hydrocortisone $20 \mathrm{mg}$ replacement in a descending scale until (10-5-5 mg) and did well. A further week later, sodium and thyroxine continued to be within the normal range, IGF1 had completely normalised, GH basal level was $2.02 \mathrm{ng} / \mathrm{mL}$, testosterone levels continued to recover, and his cortisol level at $8: 00 \mathrm{~h}$ without a morning tablet was $12 \mu \mathrm{g} / \mathrm{dL}$ (5.3-22.5). A Synacthen test was performed 6 weeks later and was completely normal, so hydrocortisone was discontinued and we took the decision to delay surgery.

The follow-up MRI at 2 months after the haemorrhage showed a $62 \%$ reduction in tumour size (Fig. 2), and at 3 months, he continued to have normal pituitary function.

\section{Discussion}

Acute apoplexy has variable behaviour that is difficult to predict, and which could be from a subacute onset to a life-threatening, clinical syndrome. Precipitating factors are not well identified in all cases and the most commonly presenting symptoms are headache, ophthalmoplegia, nausea and/or vomiting.

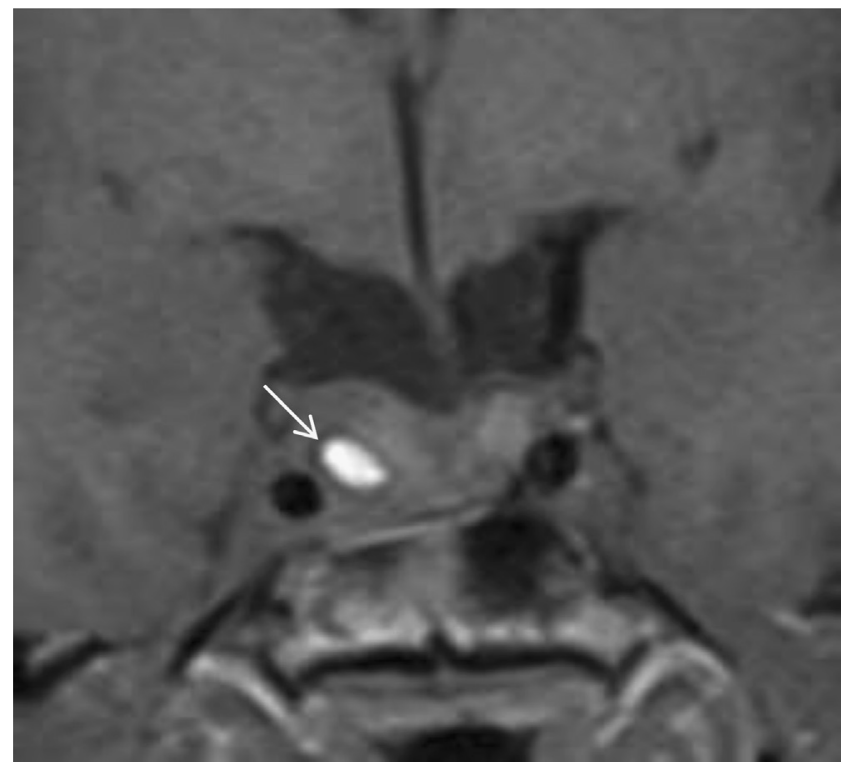

Figure 2

Follow-up coronal T1-weighted image performed 2 months later, shows a $62 \%$ reduction in tumour size. A central area of haemorrhage persists (white arrow).
Sometimes the pituitary apoplexy completely destroys the adenoma with spontaneous clinical recovery, whereas in other cases, it is a neurosurgical emergency and a remnant may regrow. Thus, the optimal management of acute pituitary apoplexy remains controversial (2).

Pituitary apoplexy has been described most frequently in non-functional pituitary adenomas but there may be some bias here, because these adenomas are generally discovered late and are usually larger than functioning adenomas. Furthermore, in many cases, if not obvious clinically, the potential functioning nature of the adenoma, when surgery is undertaken, is impossible to assess due to the extent of necrosis (2).

Partial or complete hypopituitarism is evident in most patients on presentation as, before the apoplectic episode, most will have developed the hypopituitarism as a result of mass effect on the normal pituitary. Acute adrenal insufficiency (AAI) is the most common deficit. It is also the most life-threatening hormonal complication, leading to haemodynamic problems and hyponatraemia, so intensive corticosteroid supplementation should be given to all these patients immediately, before tests results are available.

In AAI, hyponatraemia is a direct consequence of glucocorticoid deficiency. Cortisol is the strongest inhibitor of $\mathrm{ADH}$ and its deficiency could also promote a direct renal water excretion defect. Nevertheless, apoplexy also could directly irritate the hypothalamus and contribute to inappropriate antidiuretic hormone secretion (SIADH) in these patients (8). Thus in the pituitary apoplexy context, hyponatraemia can occur secondary to hypopituitarism or, rarely, to inappropriate $\mathrm{ADH}$ secretion $(7,9)$.

SIADH is defined by euvolaemic hyponatraemia and hypo-osmolality resulting from the inappropriate, constant secretion or action of ADH despite normal or increased plasma volume, which results in impaired water excretion (10). SIADH is an exclusion diagnosis; thus, the absence of other causes of hyponatraemia must be ruled out (hypocortisolism, hypothyroidism, liver, cardiac or renal dysfunctions, drug induced). Hyponatraemia must be demonstrated with corresponding hypo-osmolality, renal excretion of sodium $>30 \mathrm{mEq} / \mathrm{L}$, urine less than maximally dilute and the absence of clinical evidence of volume depletion or oedema.

This is a very rare, previously undiagnosed and untreated case of acromegaly with pituitary macroadenoma, which presented with pituitary apoplexy and associated hypopituitarism. Severe hyponatraemia developed 1 week after admission, under standard maintenance doses of hydrocortisone, with progressive 
pituitary function recovery and acromegaly remission. We diagnosed a pituitary apoplexy-related SIADH despite being uncommon, having late onset, and occurring while the patient was under well-tolerated maintenance doses of hydrocortisone.

Finally, the optimal management of acute apoplexy is a matter of debate, although the proposed European recommendations appear to be reasonable (7). They recommend shared decision-making within a multidisciplinary team, and a management strategy that is led by the clinical findings. Prompt surgical decompression is initially indicated in cases with severe or progressive impairment of visual acuity or the visual fields or with altered mental state. Patients with a mild, stable clinical picture, as with our patient, can be managed conservatively.

\section{Patient's perspective}

In the 3 years prior to the haemorrhage of my previously undetected pituitary tumour, and also unnoticed acromegaly, I had presented to my general physician with a minor case of gynaecomastia, and to a podiatrist with enlarged feet (two sizes larger and increased from normal width to double wide over the preceding 2 years). Each of these was an opportunity to perform root cause analysis and diagnose the acromegaly and to find the pituitary tumour, and in each case, we missed it. The hormone screens performed around the gynaecomastia incident did not include the full range of potentially implicated hormones (particularly, GH and IGF-1). The podiatrist evaluated the morphology of my feet and determined them normal but did not question how or why a mature adult's feet should change so much in size in a 2-year period. Acromegaly is rare, and it is forgivable that these physicians may not have been aware of it, but all of us - medical professionals and patients alike - should always ask (and insist) 'why' and not just 'what'.

During the first week after the haemorrhage of the tumour, while the immediate concern was pain management and stabilisation to presumably allow for surgery, I felt that some nursing staff in particular was insufficiently sensitive to my feedback on which medications did, or didn't, help with the pain. Concretely, the opioids did NOT seem to help much. In contrast, the dexamethasone seemed to help the most, followed by metamizole. At one point I had an unpleasant argument with the night staff over my desire to return to treatment with dexamethasone due to the headaches keeping me awake at night. The night physician responded in the negative, and that the pain was probably anxiety related; I was exhausted, my testosterone level was $23.8 \mathrm{ng} / \mathrm{mL}$ (241-827), and I was on 10-5-5 mg/daily replacement doses of hydrocortisone, and psychologically it didn't seem to be that I was anxious at all - just in pain which wasn't adequately managed.

One of my hobbies is road bicycling. During the years leading up to this medical incident, I would routinely on a weekend day ride $100 \mathrm{~km}$ over hilly terrain. This gave me strong endurance. During the hyponatraemia episode I continued to walk around, communicate, research my condition and follow my treatment. It came as a great surprise, then, 1 week after admission, that my sodium had fallen to $110 \mathrm{mmol} / \mathrm{L}$. I was not, however, asymptomatic of the growing hyponatraemia leading up to this moment. 20/20 hindsight looking at my personal notes, like 20/20 hindsight considering the gynaecomastia and enlarged feet, point to missed opportunity to have noticed the hyponatraemia earlier.

Patients must rely on their physicians' knowledge and experience. Physicians also must rely on the first-person experience, hour-by-hour and day-by-day of the patient. Medical systems/hospital protocols and staffing levels must budget enough time to allow sometimes moredetailed-than-expected interactions with a patient to ensure that physicians and medical staff can take into account the patient's possibly medically valuable input, although it may be not medically accurate. Systems and protocols and physicians also should provide medical information in advance and in writing wherever possible. All of this is especially true in cases of rare diseases with complex and varying presentation, such as pituitary apoplexy, where optimal management remains controversial.

In my personal case, I was fortunate to have extensive support by family and friends, allowing me to take copious notes from the first hours and to research my condition on a constant basis as treatment progressed. This allowed me to raise many questions - some medically relevant, others erroneous, and even to detect certain curiosities in the administration of treatment, fortunately none of which resulted in important medical impacts to my recovery but which in the complex context of pituitary apoplexy might have had such an impact on another patient. It is from this perspective that I insist on my assertion above, the medical systems must allow physicians the resources, and physicians must use those resources to consider patients' possibly detailed (and possibly erroneous) input throughout treatment.

I felt at various times throughout treatment that my physicians were working under conditions of stressed resources, above all the availability of their time. I wished for information about certain tests and schedules in writing, as despite my unusual capacity for note taking and research, the amount of information provided verbally still was overwhelming, and I at times was left wondering 'why?' and 'when/what next?'. And I missed a couple of verbal-only instructions which fortunately produced only minor inconveniences.

I have participated actively in the redaction of this case study, and I make my comments above with the same intention as the physicians responsible for this case study themselves present the study: to assist the global medical community in the optimal management of this and other complex conditions, the optimal acute treatment of which remain controversial.

I am convinced of the excellent experience and never-failing good intentions of the physicians and medical staff who attended my case, and I will be forever grateful for their efforts and results.

\section{Declaration of interest}

The authors declare that there is no conflict of interest that could be perceived as prejudicing the impartiality of the research reported.

\section{Funding}

This research did not receive any specific grant from any funding agency in the public, commercial, or not-for-profit sector.

\section{Patient consent}

Written informed consent has been obtained from the patient for publication of the case report and the accompanying images.

\section{Author contribution statement}

B B was responsible for case description, literature review, writing and editing; $\mathrm{SE}$ is an endocrinology resident and provided clinical care for the patient; A F is a neurosurgeon; S S is a radiologist and provided MRI images and descriptions. 


\section{References}

1 Verrees M, Arafah BM \& Selman WR. Pituitary tumor apoplexy: characteristics, treatment, and outcomes. Neurosurgical Focus 200416 1-2. (https://doi.org/10.3171/foc.2004.16.4.7)

2 Briet C, Salenave S, Bonneville JF, Laws ER \& Chanson P. Pituitary apoplexy. Endocrine Reviews 201536 622-645. (https://doi. org/10.1210/er.2015-1042)

3 Roerink SHPP, van Lindert EJ \& van de Ven AC. Spontaneous remission of acromegaly and Cushing's disease following pituitary apoplexy: two case reports. Netherlands Journal of Medicine 201573 242-246.

4 Soni A, De Silva SR, Allen K, Byrne JV, Cudlip S \& Wass JAH. A case of macroprolactinoma encasing an internal carotid artery aneurysm, presenting as pituitary apoplexy. Pituitary 200811 307-311. (https:// doi.org/10.1007/s11102-007-0063-5)

5 Mir SA, Masoodi SR, Bashir MI, Wani AI, Farooqui KJ, Kanth B \& Bhat AR. Dissociated hypopituitarism after spontaneous pituitary apoplexy in acromegaly. Indian Journal of Endocrinology and
Metabolism 201317 S102-S104. (https://doi.org/10.4103/2230$8210.119518)$

6 Nishioka H, Haraoka J \& Miki T. Spontaneous remission of functioning pituitary adenomas without hypopituitarism following infarctive apoplexy: two case reports. Endocrine Journal 200552 117-123. (https://doi.org/10.1507/endocrj.52.117)

7 Capatina C, Inder W, Karavitaki N \& Wass JAH. MANAGEMENT of ENDOCRINE DISEASE: Pituitary tumour apoplexy. European Journal of Endocrinology 2015172 R179-R190. (https://doi.org/10.1530/EJE14-0794)

8 Fountas A, Andrikoula M \& Tsatsoulis A. A 45 year old patient with headache, fever, and hyponatraemia. BMJ 2015350 h962. (https:// doi.org/10.1136/bmj.h962)

9 Agrawal D \& Mahapatra AK. Pituitary apoplexy and inappropriate ADH secretion. Journal of Clinical Neuroscience 200310 260-261. (https://doi.org/10.1016/S0967-5868(03)00002-X)

10 Cuesta $\mathrm{M} \&$ Thompson CJ. The syndrome of inappropriate antidiuresis (SIAD). Best Practice and Research: Clinical Endocrinology and Metabolism 201630 175-187. (https://doi.org/10.1016/j. beem.2016.02.009)

Received in final form 11 June 2019

Accepted 26 June 2019 